\title{
A randomized controlled trial comparing autologous cranioplasty with custom-made titanium cranioplasty
}

\author{
Stephen Honeybul, FRCS(SN), FRACS, ${ }^{1,2}$ David Anthony Morrison, PhD, ${ }^{3}$ \\ Kwok M. Ho, FCICM, PhD, ,,5,7 Christopher R. P. Lind, FRACS, ${ }^{1,2,6}$ and \\ Elizabeth Geelhoed, PhD, MPH, BEc, DipNucMed ${ }^{5}$
}

\begin{abstract}
1Department of Neurosurgery, Sir Charles Gairdner Hospital, Nedlands; Departments of ${ }^{2}$ Neurosurgery, ${ }^{3}$ Medical Engineering and Physics, and ${ }^{4}$ Intensive Care, Royal Perth Hospital, Perth; Schools of ${ }^{5}$ Population Health and ${ }^{6}$ Surgery, University of Western Australia, Perth; and ${ }^{7}$ School of Veterinary \& Life Sciences, Murdoch University, Perth, Western Australia, Australia
\end{abstract}

\begin{abstract}
OBJECTIVE Autologous bone is usually used to reconstruct skull defects following decompressive surgery. However, it is associated with a high failure rate due to infection and resorption. The aim of this study was to see whether it would be cost-effective to use titanium as a primary reconstructive material.
\end{abstract}

METHODS Sixty-four patients were enrolled and randomized to receive either their own bone or a primary titanium cranioplasty. All surgical procedures were performed by the senior surgeon. Primary and secondary outcome measures were assessed at 1 year after cranioplasty.

RESULTS There were no primary infections in either arm of the trial. There was one secondary infection of a titanium cranioplasty that had replaced a resorbed autologous cranioplasty. In the titanium group, no patient was considered to have partial or complete cranioplasty failure at 12 months of follow-up $(p=0.002)$ and none needed revision $(p=$ 0.053). There were 2 deaths unrelated to the cranioplasty, one in each arm of the trial. Among the 31 patients who had an autologous cranioplasty, 7 patients (22\%) had complete resorption of the autologous bone such that it was deemed a complete failure. Partial or complete autologous bone resorption appeared to be more common among young patients than older patients ( 32 vs 45 years old, $p=0.013$ ). The total cumulative cost between the 2 groups was not significantly different (mean difference $\mathrm{A} \$ 3281,95 \% \mathrm{Cl} \$-9869$ to $\$ 3308 ; p=0.327$ ).

CONCLUSIONS Primary titanium cranioplasty should be seriously considered for young patients who require reconstruction of the skull vault following decompressive craniectomy.

Clinical trial registration no.: ACTRN12612000353897 (anzctr.org.au)

http://thejns.org/doi/abs/10.3171/2015.12.JNS152004

KEY WORDS decompressive craniectomy; autologous cranioplasty; titanium cranioplasty; randomized controlled trial; surgical technique

$\mathrm{O}$ VER the past 2 decades, there has been a global resurgence of interest in the use of decompressive craniectomy in the management of neurological emergencies..$^{15}$ Numerous studies have described the use of the procedure not only in the context of severe traumatic injury ${ }^{21}$ and ischemic stroke ${ }^{23}$ but also following subarachnoid hemorrhage, ${ }^{8}$ severe intracranial infection, ${ }^{2}$ dural sinus thrombosis, ${ }^{7}$ and inflammatory conditions. ${ }^{5}$ Once the patient has recovered from the neurological condition that necessitated the decompressive surgery and the cerebral swelling has subsided, a cranioplasty is required to reconstruct the cranial defect. This is important to restore cerebral protection ${ }^{14}$ and cosmesis, and, in certain patients, it can improve neurological function, possibly by reestablishing cerebrospinal fluid dynamics and cerebral blood flow. 10,16,18,20,24

The material most commonly used for reconstruction has been the patient's own bone that has been stored in a refrigerated sterile container. The rationale for this is that autologous bone fulfills many of the requirements of an ideal reconstructive material. It is cheap, biocompatible, strong, radiolucent, and, being the patient's own skull, it has an ideal contour. However, over recent years a number of studies have demonstrated that use of autologous bone is associated with a high failure rate due to either infection or bony resorption. ${ }^{6,11,16,20}$ When this occurs, the original 
bone flap often has to be discarded and consideration must be given to alternative alloplastic material.

Titanium is one such material that has been used for many years because of its strength and biocompatibility, and advances in computer-assisted design and manufacturing $(\mathrm{CAD} / \mathrm{CAM})$ have enabled the production of large custom-made prefabricated plates. ${ }^{25}$ Favorable long-term functional and aesthetic outcomes have been reported, and these plates would seem to represent a viable alternative to autologous bone; however, one of the main disadvantages is cost. Cost could possibly preclude the use of plates as a primary reconstructive material if this additional cost cannot be offset by a reduction in hospital readmissions for augmentation of failed bone flaps.

The aim of this study was to compare the long-term aesthetic and functional outcomes and the cost-effectiveness of primary autologous bone versus primary prefabricated titanium cranioplasty.

\section{Methods}

This prospective randomized controlled trial was approved by the human research ethics committees from the 2 hospitals that provide neurosurgical services in Western Australia and was registered with Australian and New Zealand Clinical Trials Registry (clinical trial registration no. ACTRN12612000353897, http://www.anzctr.org. au). Sixty-four patients were enrolled and randomized to receive either their own bone that had been stored in a refrigerator at $-80^{\circ} \mathrm{C}$ or a primary titanium cranioplasty.

\section{Inclusion and Exclusion Criteria}

All adult patients ( $>18$ years) who underwent a decompressive craniectomy and had their own bone available for the subsequent cranioplasty procedure were considered eligible for the study. Patients were excluded from the study for the following reasons: if they had undergone decompressive craniectomy but did not have their own bone available for the subsequent cranioplasty procedure, if they had a bone flap available but it had been damaged or comminuted, if they had an intracranial infection following craniectomy, and if they had sustained a penetrating brain injury.

\section{Recruitment Process and Consent for Various Capacities of the Patients}

Patients with cognitive capacity such that they could provide informed consent were provided with information about the project and were asked to consent to participate at the time of recruitment. For those patients with impaired cognitive capacity such that they were unable to provide informed consent, a waiver of consent was used. Next of kin were provided with information about the project and were asked to sign an acknowledgment form on behalf of the patient. Patients who regained cognitive capacity during the project were provided with information about the project and asked to sign a "confirmation of consent" form to continue participating in the study.

\section{Randomization}

Patients were randomized approximately 6 weeks prior to their planned cranioplasty procedure so that there was sufficient time in which to construct a titanium plate if required. They were randomized according to a randomnumber sequence generated by random-number software. All randomization numbers were concealed inside sequentially numbered sealed envelopes. Patients and relatives were blinded to their allocation.

\section{Manufacture of Custom-Made Titanium Cranioplasties}

From a high-resolution helical multislice CT scan of the patient's head, a virtual 3D model of the skull was generated, and, from this, a rapid-prototype model of the cranial defect was created. Using a combination of software packages, the margins of the defect were isolated and the surface was interpolated from the extant bone. The fit of the rendered surface was qualitatively assessed by viewing the 3D model of the skull with and without the repaired surface in place. Once the rendered surface was seen to be a good fit, a rapid-prototype mold was created for pressing the titanium plate.

The plates were manufactured from medical-grade titanium sheet (ASTM-F67-98), ranging in thickness from 0.6 to $1.0 \mathrm{~mm}$ depending on the area to be covered and the depth of the pressing required. The titanium sheet was hydrostatically pressed into the mold, cut to shape, slotted and tabbed on the periphery, polished, heat treated at $540^{\circ} \mathrm{C}$, bead blasted, laser marked (with patient identification and orientation information), cleaned ultrasonically, and passivated in 30\% nitric acid. Each plate was try-fitted to the rapid-prototype model to ensure that the surface contours were smooth and the orientation was unambiguous (Fig. 1). The plates were sterilized using standard steam sterilization prior to surgery. ${ }^{4}$

\section{Surgical Procedure}

All surgical procedures were performed by a senior consultant neurosurgeon (S.H.) to limit possible confounding due to differences in surgical technique and surgical expertise within and between treatment arms. The procedure was performed when cerebral swelling had subsided and the patient was medically stable. Following endotracheal intubation, the patient was placed on the operating table with the head supported on a head ring. A single dose of a broad-spectrum antibiotic agent was given intravenously at induction of anesthesia. The patient's hair was completely removed with a margin of at least $3 \mathrm{~cm}$ from the incision line using a propriety hair shaver. Great care was taken to avoid skin damage. The scalp was then vigorously washed with $30-60 \mathrm{ml}$ of an aqueous solution of chlorhexidine gluconate $(15 \mathrm{mg} / 30 \mathrm{ml})$ and cetrimide $(150 \mathrm{mg} / 30 \mathrm{ml})$ and then left to dry. A red-tinted alcoholic skin preparation (chlorhexidine $2 \%$ in ethanol $70 \%$ ) was then applied and again left to dry. No operating room staff was allowed near the patient at this stage, and the operative staff then proceeded to scrub, gown, and glove (single gloving). Cotton drapes with an underling plastic sheet were then placed around the incision line and secured with skin staples. Care was taken to avoid hair contamination and to leave a gap of approximately $2 \mathrm{~cm}$ between the edge of the drapes and the incision line. An iodine-impregnated incision drape was placed over the exposed skin, and care was taken to ensure that all surfaces were covered. 


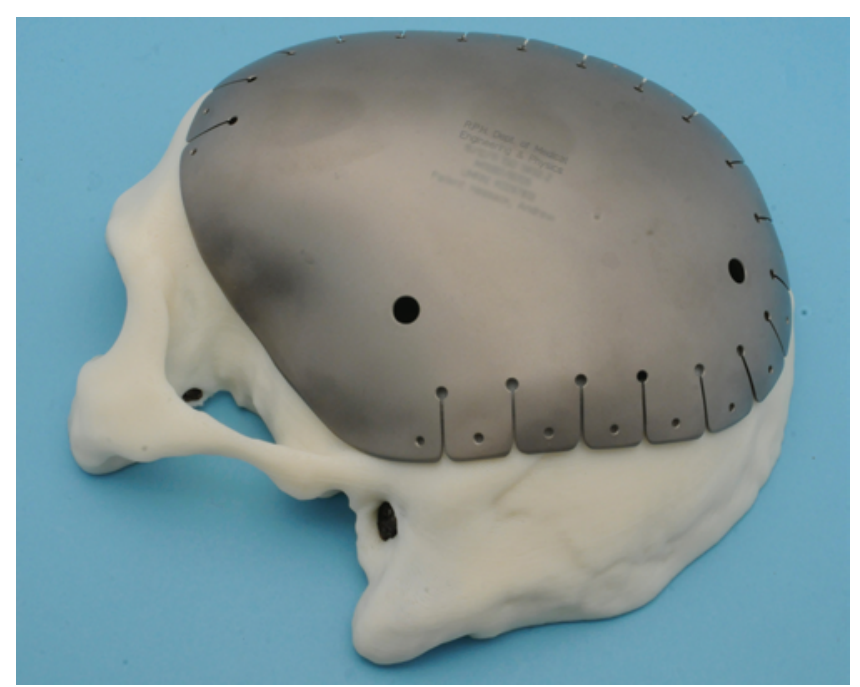

FIG. 1. An example of a titanium plate seen on the rapid-prototype model. Figure is available in color online only.

A whole-body drape with a clear adhesive opening was then placed over the entire patient. This was further stapled around the margins of the incision line to ensure that the iodinated drape remained in contact with the skin. A local anesthetic agent was then infiltrated along the line of the incision (bupivacaine with adrenaline 1:200,000). At this stage, if an autologous cranioplasty was to be performed, it was removed from its refrigerated container and placed in a warm saline solution. At the time of surgical decompression, the autologous bone was double-wrapped in sterile plastic, placed in a nonsterile plastic container, and stored in a designated cranioplasty refrigerator at a constant $-80^{\circ} \mathrm{C}$.

The wound was then opened using a scalpel and sharp dissection. Surgical gauze was placed along both sides of the incision and secured with single-use synthetic scalp clips. Care was taken to incorporate the iodine-impregnated drape to minimize scalp contamination. Once the scalp flap was reflected, the temporalis muscle was usually dissected from the dura and reflected laterally. However, if it was densely adherent, it was left attached to the dura and the cranioplasty was placed on top of both structures. The bone margins were then fully exposed. In the case of titanium cranioplasty, a further 1-cm circumferential dissection was performed to accommodate the required overlap (Fig. 1).

The cranioplasty was then placed in position to ensure adequate fit. It was then removed, rinsed in normal saline, covered with aqueous iodine, and left to completely dry. Meanwhile, a wound drain was positioned, ensuring that the trocar exited through skin covered by the iodine-impregnated incision drape. Iodine-soaked packs were then placed around the edges of the incision.

The dry cranioplasty was then secured using 5-mm titanium self-tapping screws, the wound drain was positioned, and the wound was closed in a layer with 2-0 blanket nylon sutures. A CT scan was obtained the following day, and, if there was no postoperative collection, the wound drain was removed. Sutures were removed on Day 10 by the nurses on the neurosurgical ward.

\section{Outcome Measures}

\section{Primary Outcome Measure: Implant Failure Requiring} Reoperation

Implant failure requiring reoperation could have been due to infection (defined as an infected cranioplasty that required removal of the implant and systemic antibiotic therapy) or autologous bone flap resorption (assessed using CT scans following the immediate autologous cranioplasty and at 12 months. The assessment was performed by the senior neurosurgeon [S.H.], and criteria are shown in Table 1).

\section{Secondary Outcome Measures}

Secondary outcome measures included the following: 1) Adverse events (occurring at any time point within 12 months). These events included neurological deterioration following cranioplasty; development of postoperative collections in the subgaleal, epidural, or subdural space; and an increase in epileptic seizure rates. 2) Cosmetic and functional outcome. This was assessed at 12 months by both the patient's neurosurgeon (S.H.) and the patient himor herself (Table 2). In the cosmetic assessment, a minor degree of temporal hollowing was deemed acceptable. The functional assessment involved clinical palpation of the defect to determine how effective the material had restored the functional contour of the skull. In the presence of neurocognitive deficit such that the patient was unable to provide an opinion, the opinion of the primary caregiver was requested. The overall outcome of cranioplasty was graded according to the lowest level achieved in one of the 4 components of assessment; i.e., to be graded a complete success it had to be deemed a complete success in all aspects by both the patient and the neurosurgeon (S.H.). If it was deemed functionally a complete success but there were minor cosmetic problems, it was deemed a partial success. 3) Total hospital costs incurred by the 2 groups of patients over a 1-year period. This included manufacture of the custom-made titanium cranioplasty plate $(\mathrm{A} \$ 3500$; all costs are presented in Australian dollars) (both as a

TABLE 1. Assessment of autologous bone flap resorption $(n=31)$

\begin{tabular}{ccc}
\hline Assessment & \multicolumn{1}{c}{ Radiological Criteria } & $\begin{array}{c}\text { No. of } \\
\text { Patients } \\
\text { (at 1 yr) }\end{array}$ \\
\hline $\begin{array}{c}\text { Complete } \\
\text { success }\end{array}$ & $\begin{array}{c}\text { Fusion at anterior craniectomy margins \& } \\
\text { no evidence of bone resorption* }\end{array}$ & 12 \\
\hline $\begin{array}{c}\text { Partial suc- } \\
\text { cess }\end{array}$ & $\begin{array}{c}\text { No fusion at craniectomy margins but } \\
\text { minimal evidence of bone resorption }\end{array}$ & 5 \\
\hline $\begin{array}{c}\text { Satisfactory } \\
\text { Partial failure }\end{array}$ & $\begin{array}{c}\text { Some resorption but cerebral protection } \\
\text { is satisfactory }\end{array}$ & 4 \\
\hline $\begin{array}{c}\text { Erosion through both tables of calvaria } \\
\text { or w/ significant gaps in the skull such } \\
\text { that cerebral protection is potentially } \\
\text { compromised }\end{array}$ & 3 \\
\hline Complete & $\begin{array}{c}\text { Loss of cerebral protection-requires } \\
\text { augmentation }\end{array}$ & 7 \\
\hline
\end{tabular}

* Anterior fusion was assessed because the bone flap was routinely moved forward to achieve a good cosmetic result. 


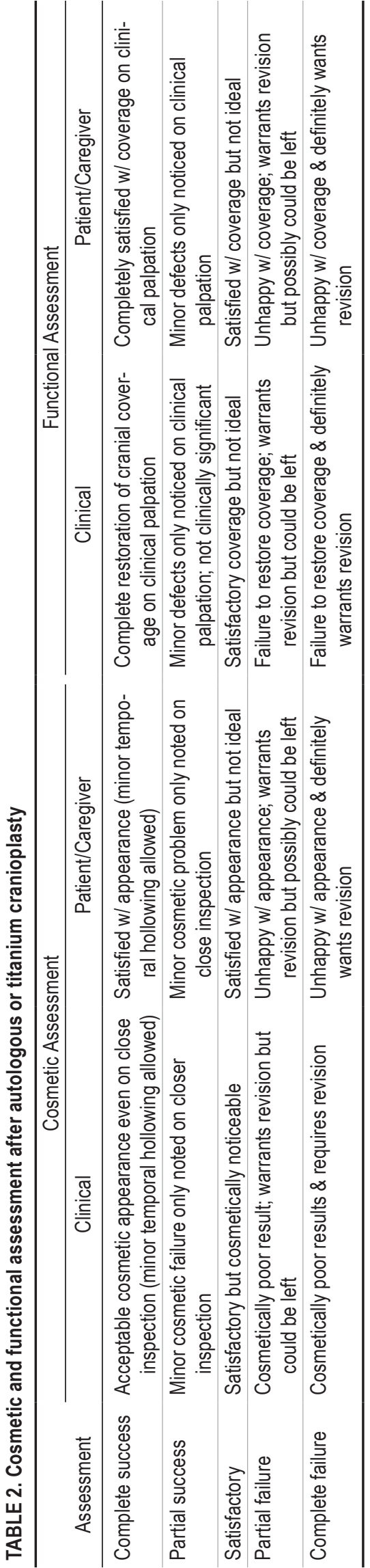

primary procedure and as a secondary procedure in cases in which the primary material failed) ${ }^{4}$ total number of neurosurgical operations ( $\$ 25,000$ per 2 hours operation), and length of additional hospital days (\$1000 per ward day) including ICU stay (\$3500 per day) due to complications (excluding ongoing hospital inpatient requirements), total antibiotic-days, and total operating room time. ${ }^{12}$ The number of items of significant cost were measured (e.g., costs of titanium plates), but the actual total costs were estimated using average costs (e.g., days in the hospital) associated with each item as costed in Australia in 2011. No cost analysis was incorporated for the bone flap storage. At the 2 neurotrauma institutions in Western Australia, the bone flaps are stored in-house within a designated bone flap refrigerator, and, as such, the financial implications are negligible.

\section{Statistical Analysis}

Our previous experience showed that more than $32 \%$ of patients requiring decompressive craniectomy had complications related to either infections of the autologous cranioplasty or significant bone resorption compared with a less than 5\% complication rate of using primary titanium cranioplasty. ${ }^{13,17}$ Assuming $\mathrm{p}<0.05$ as statistically significant and a power of $80 \%$ for the study, we calculated that 32 subjects in each group were needed to demonstrate a $25 \%$ difference in rates of satisfactory cosmetic and functional outcomes due to bone resorption after primary cranioplasty. Overall, 64 patients were therefore required. All analyses were conducted according to an intentionto-treat basis. Categorical and continuous outcomes with skewed distributions were analyzed by chi-square and Mann-Whitney tests, respectively. All analyses were conducted using SPSS for Windows (version 22.0, IBM), and a $\mathrm{p}$ value $<0.05$ was taken as significant.

\section{Results}

The period of study was from early 2012 to mid-2015. During that time period, 64 patients were randomized from a possible 105 patients who required a cranioplasty procedure (Fig. 2). The patients randomized to either group were similar with respect to their baseline characteristics (Table 3).

\section{Primary Outcome Measures: Implant Failure Requiring Reoperation \\ Infection}

There were no primary infections in either the autologous or titanium arms of the trial. One patient who required a titanium cranioplasty due to autologous cranioplasty resorption presented 3 weeks after surgery with clinical and radiological evidence of infection. The titanium cranioplasty was removed, and Staphylococcus aureus was cultured. The patient required 8 weeks of antibiotics before the sterilized titanium cranioplasty was reimplanted. It was initially thought that the autologous cranioplasty had resorbed due to a subclinical infection; however, at the time of removal of the bone flap the patient was afebrile with normal hematological parameters, and there was no growth from cultures of the resorbed autologous cranioplasty. 


\section{Patients requiring cranioplasty during the study years 2012/15}

$(n=105)$

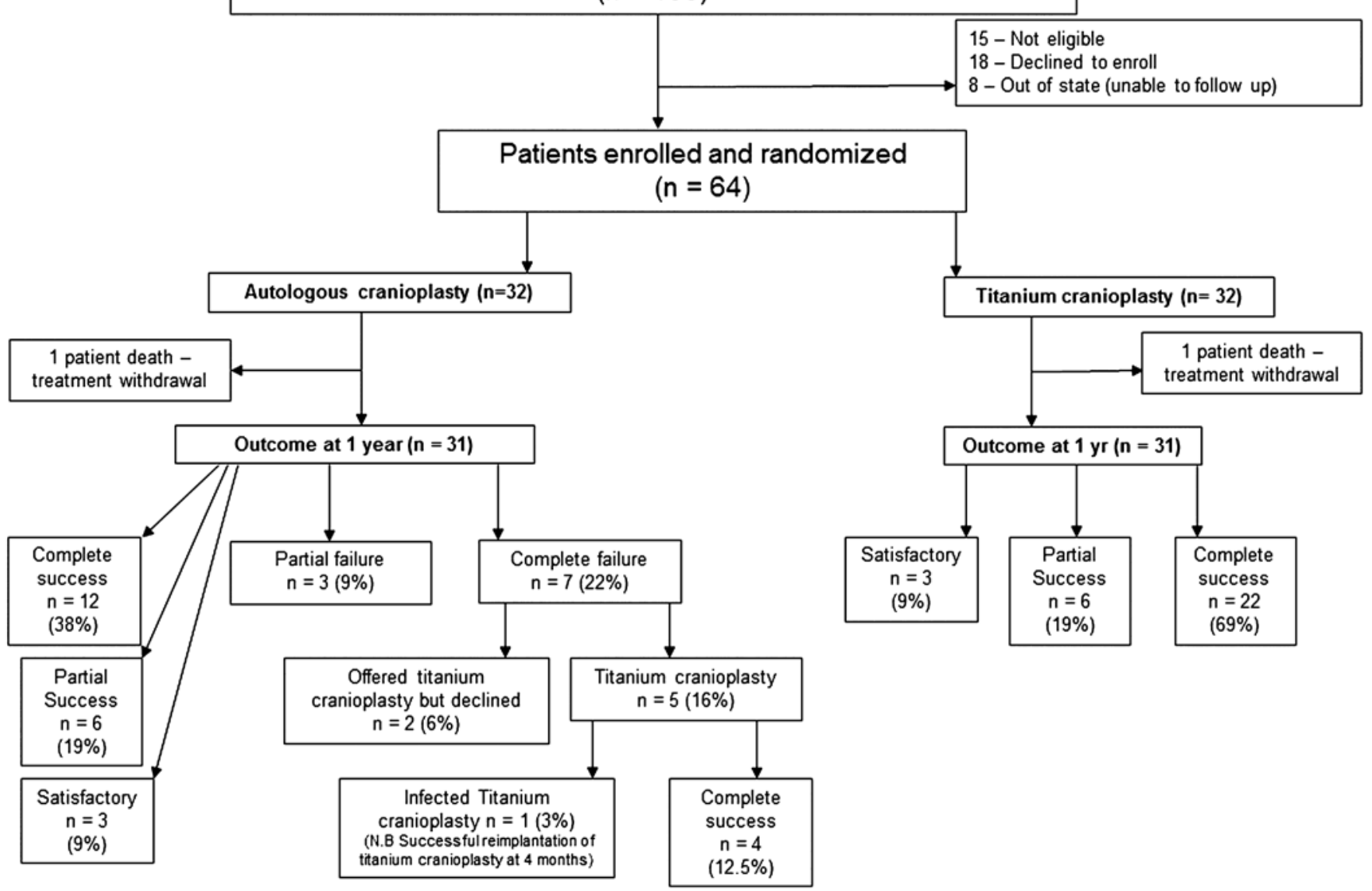

FIG. 2. Flowchart of the patients included in the study. All titanium cranioplasties were deemed successful in that none required revision. Twenty-two (69\%) were deemed a complete success in that that they fulfilled our cosmetic and functional requirements. Twenty-one (66\%) autologous cranioplasties were deemed successful, and $7(22 \%)$ failed because they required revision.

\section{Autologous Bone Flap Resorption}

Among the 31 patients who had an autologous cranioplasty for whom radiological assessment was available, 7 patients $(22 \%)$ had complete resorption of the autologous bone such that it was deemed a complete failure (Table 1 and Fig. 3). Five of these patients agreed to undergo a secondary cranioplasty with a titanium plate. The remaining 2 patients declined augmentation. Both had fairly thick hair such that the deformity was not noticeable on clinical inspection, and neither was keen on undergoing further

TABLE 3. Characteristics of the patients who were randomized to have primary autologous or titanium cranioplasty after decompressive craniectomy

\begin{tabular}{llccc}
\hline \multicolumn{1}{c}{ Variable } & All $(\mathrm{n}=64)$ & Titanium $(\mathrm{n}=32)$ & Autologous $(\mathrm{n}=32)$ & $\mathrm{p} \mathrm{Value^{* }}$ \\
\hline Age, yrs (IQR) & $44(31-58)$ & $45(33-54)$ & $41(24-60)$ & 0.963 \\
\hline Male, no. (\%) & $45(70)$ & $21(66)$ & $24(75)$ & 0.585 \\
\hline Reason for decompressive craniectomy, no. (\%) & & & 0.473 \\
\hline TBI & $43(67)$ & $19(59)$ & $24(75)$ & \\
Ischemic stroke & $9(14)$ & $5(16)$ & $4(12.5)$ & \\
Hemorrhagic stroke & $11(17)$ & $7(22)$ & $4(12.5)$ & $0(0)$ \\
Tumor & $1(2)$ & $1(3)$ & $27(84)$ & 0.999 \\
\hline Unilateral craniectomy, no. (\%) & $55(86)$ & $28(88)$ & $87(63-129)$ & 0.401 \\
\hline Time btwn craniectomy \& cranioplasty, days (IQR) & $89(67-125)$ & $92(73-125)$ & & \\
\hline
\end{tabular}

$\mathrm{IQR}=$ interquartile range; $\mathrm{TBI}=$ traumatic brain injury.

* Mann-Whitney test or chi-square test. 


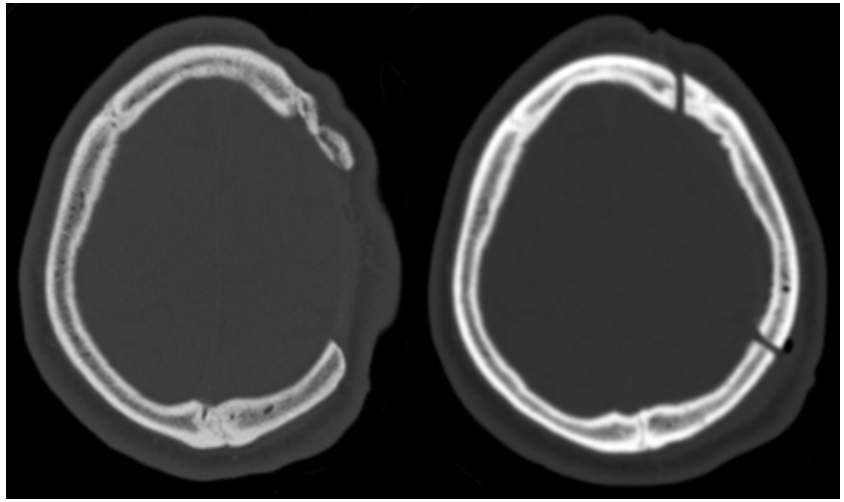

FIG. 3. Axial CT scans obtained in a 29 -year-old man 9 months following an autologous cranioplasty. The cranioplasty is deemed a complete failure because it failed to restore cranial coverage and therefore protect the underlying brain

surgical procedures. Partial or complete autologous bone resorption appeared to be more common among young patients than older patients (32 vs 45 years old, $\mathrm{p}=0.013$ ). In 12 patients, there was clear evidence at the anterior margins such that the cranioplasty was deemed a complete success (Fig. 4).

\section{Secondary Outcome Measures \\ Cosmetic and Functional Outcomes}

Among the 31 patients who had autologous cranioplasty for whom 12-month clinical and radiological assessments were available, 21 were deemed to have had at least a satisfactory outcome, 12 were deemed to have had a completely successful result from a cosmetic and functional perspective, and 10 were deemed to have had either a partial or complete failure (Fig. 2). In the titanium group, no patient was considered to have had a partial or complete cranioplasty failure at 12 months of follow-up $(p=0.002)$ (Table 4), and none needed revision $(\mathrm{p}=0.053)$.

\section{Deaths}

Two patients died during the study period, one from each arm of the trial. Both patients had sustained severe traumatic brain injuries, were making poor neurological progress, and died as a consequence of treatment withdrawal. One patient died at 4 months following cranioplasty and the other at 6 months; neither death was felt to be related to the cranioplasty procedure.

\section{Complications and Cost Outcomes}

There were no significant differences in the incidence of postoperative complications, specifically, postoperative hematoma $(\mathrm{p}=0.708)$ or seizures $(\mathrm{p}=0.708)$ between the 2 groups. The cumulative length of hospital stay within 12 months after cranioplasty was not significantly different between the 2 groups $(p=0.077)$, and the total cumulative cost was also not significantly different (mean difference $\$ 3281$ [95\% CI \$-9869 to \$3308], $p=0.327$ ) (Table 5).

\section{Discussion}

This study represents the first prospective random-

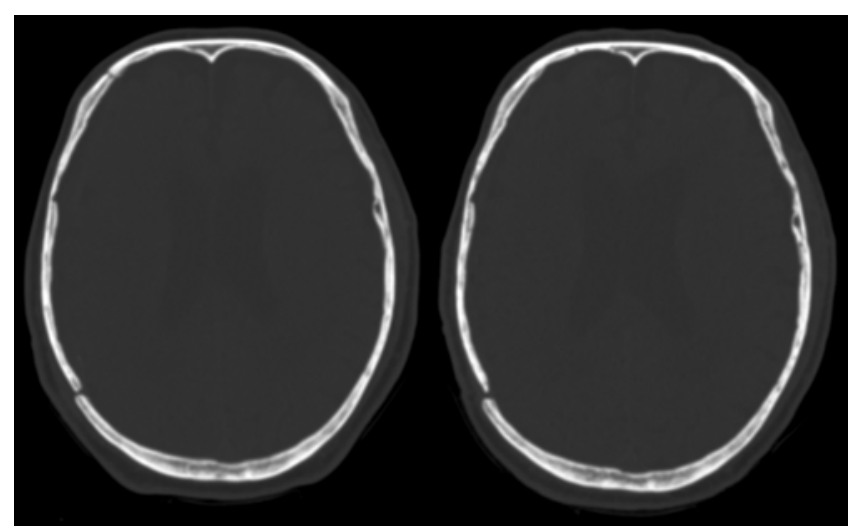

FIG. 4. Axial CT scans obtained in a 52-year-old woman 1 year following an autologous cranioplasty. The cranioplasty was deemed a complete success because of the excellent contour with anterior bone fusion.

ized controlled trial comparing autologous cranioplasty with an industrial patient-specific implant. The hypothesis upon which the trial was based was that primary titanium cranioplasty improves cerebral protection by avoiding the frequent problem of bone resorption requiring reoperation, and this would offset the higher initial outlay cost of titanium plates.

Overall, the findings are consistent with recent published literature regarding bone flap resorption as it is becoming increasingly apparent that many bone flaps undergo aseptic necrosis such that cranial protection is compromised..$^{11,13,24}$ This trial has also confirmed that the cranioplasty procedure is not without significant complications, although the very low rate of primary infections requires further consideration.

\section{Bone Flap Resorption}

The reported incidence of bone flap resorption varies widely, from as low as $4 \%$ to as high as $50 \% .6,11,13,19,22$ This is probably because there is a variation in both the definitions on what constitutes significant bone resorption and timing and methodology of follow-up for patients having autologous cranioplasty. In this study we used clinical assessments by both the patients and the treating study neurosurgeon, as well as radiological assessments at a standardized 12-month time point after cranioplasty, as previous studies have indicated that most resorption occurs within this time period. ${ }^{16}$

There will always be some degree of subjectivity when making these types of assessments, although for those bone flaps that were deemed to be a complete failure, there was little doubt that cranial protection was compromised. However, as noted by Stieglitz et al., ${ }^{24}$ a number of patients with significant resorption did not spontaneously report this occurrence and were unaware that there was a potential problem. This highlights the need for longterm clinical and radiological surveillance, especially in young adults. Whether radiological surveillance beyond 12 months is required is yet to be determined.

\section{Infection}

The reported incidence of cranioplasty infection is 
TABLE 4. Outcomes of the patients who were randomized to have primary autologous or titanium cranioplasty after decompressive craniectomy

\begin{tabular}{|c|c|c|c|c|}
\hline Variable & All $(n=64)$ & Titanium $(n=32)$ & Autologous $(n=32)$ & p Value* \\
\hline Median postop hospital stay, days (IQR) & $3(3-3)$ & $3(3-3)$ & $3(3-3)$ & 0.077 \\
\hline Postop hematoma or effusion, no. (\%) & $8(12.5)$ & $5(16)$ & $3(9)$ & 0.708 \\
\hline Postop hematoma or effusion requiring evacuation, no. (\%) & $3(5)$ & $2(6)$ & $1(3)$ & 0.999 \\
\hline Seizure, no.† & $8(12.5)$ & $3(9)$ & $5(16)$ & 0.708 \\
\hline Infected bone flap or titanium plate, no. (\%) & $1(2)$ & $1(3)$ & $0(0)$ & 0.999 \\
\hline $\begin{array}{l}\text { Required revision cranioplasty due to unsuccessful primary } \\
\text { cranioplasty, no. (\%) }\end{array}$ & $5(8)$ & $0(0)$ & $5(16)$ & 0.053 \\
\hline $\begin{array}{l}\text { Partial or complete failure after the primary cranioplasty con- } \\
\text { sidering a combination of cosmetic, functional, \& radiological } \\
\text { criteria, no. (\%) } \ddagger\end{array}$ & $10(16)$ & $0(0)$ & $10(31)$ & 0.001 \\
\hline \multicolumn{5}{|l|}{ Overall outcome of the primary cranioplasty, no. (\%)§ } \\
\hline Complete failure & $7(11)$ & $0(0)$ & $7(22)$ & \\
\hline Partial failure & $3(5)$ & $0(0)$ & $3(9)$ & \\
\hline Satisfactory & $6(9)$ & $3(9)$ & $3(9)$ & \\
\hline Partial success & $12(19)$ & $6(19)$ & $6(19)$ & \\
\hline Complete success & $34(53)$ & $22(69)$ & $12(38)$ & 0.024 \\
\hline \multicolumn{5}{|l|}{ Cosmetic appearance assessed by the patient, no. (\%)§ } \\
\hline Complete failure & $7(11)$ & $0(0)$ & $7(22)$ & \\
\hline Partial failure & $0(0)$ & $0(0)$ & $0(0)$ & \\
\hline Satisfactory & $7(11)$ & $1(3)$ & $6(19)$ & \\
\hline Partial success & $11(17)$ & $4(12.5)$ & $7(22)$ & \\
\hline Complete success & $37(58)$ & $26(81)$ & $11(34)$ & 0.002 \\
\hline \multicolumn{5}{|l|}{ Cosmetic appearance assessed by the assessor, no. (\%)§ } \\
\hline Complete failure & $7(11)$ & $0(0)$ & $7(22)$ & \\
\hline Partial failure & $1(2)$ & $0(0)$ & $1(3)$ & \\
\hline Satisfactory & $8(12.5)$ & $2(6)$ & $6(19)$ & \\
\hline Partial success & $10(16)$ & $4(12.5)$ & $6(19)$ & \\
\hline Complete success & $36(56)$ & $25(78)$ & $11(34)$ & 0.007 \\
\hline \multicolumn{5}{|l|}{ Functional outcome assessed by the patient, no. (\%)§ } \\
\hline Complete failure & $7(11)$ & $0(0)$ & $7(22)$ & \\
\hline Partial failure & $0(0)$ & $0(0)$ & $0(0)$ & \\
\hline Satisfactory & $6(9)$ & $0(0)$ & $6(19)$ & \\
\hline Partial success & $10(16)$ & $3(9)$ & $7(22)$ & \\
\hline Complete success & $39(61)$ & $28(88)$ & $11(34)$ & 0.001 \\
\hline \multicolumn{5}{|l|}{ Functional outcome assessed by the assessor, no. (\%)§ } \\
\hline Complete failure & $7(11)$ & $0(0)$ & $7(22)$ & \\
\hline Partial failure & $1(2)$ & $0(0)$ & $1(3)$ & \\
\hline Satisfactory & $6(9)$ & $1(3)$ & $5(16)$ & \\
\hline Partial success & $10(16)$ & $3(9)$ & $7(22)$ & \\
\hline Complete success & $38(59)$ & $27(84)$ & $11(34)$ & 0.002 \\
\hline
\end{tabular}

relatively high. ${ }^{3,9,20,26}$ Within the Western Australian statewide neurosurgical service, the overall infection rate for cranial procedures has been consistently audited at $1 \%-2 \%$; however, our previous studies have also demonstrated a high cranioplasty infection rate, consistent with some other reports. ${ }^{13,17}$ It is unknown why it is so high; a number of reasons have been proposed, including skin colonization while in the hospital, uncertain sterility with long-term storage of the bone flap, and reduced immune response following major brain injury trauma and reop- 
TABLE 5. Total costs due to different items during the 12-month follow-up period after primary autologous or titanium cranioplasty after decompressive craniectomy*

\begin{tabular}{lrr}
\hline \multicolumn{1}{c}{ Cost } & Titanium $(\mathrm{n}=32)$ & \multicolumn{1}{c}{ Autologous $(\mathrm{n}=32)$} \\
\hline Titanium plates (\$350/plate) & $\$ 112,000$ & $\$ 17,500$ \\
\hline Hospital ward stay (\$1000/day) & $\$ 97,000$ & $\$ 132,000$ \\
\hline ICU stay (\$3500/day) & $\$ 0$ & $\$ 28,000$ \\
\hline Operating room \& surgical costs (\$25,000/2 hrs operation) & $\$ 800,000$ & $\$ 1,150,000$ \\
\hline Antibiotics for an infected flap (flucloxacillin \$20/5 g IV \& 12 g oral) & $\$ 0$ & $\$ 480$ \\
\hline Total cost & $\$ 1,009,000$ & $\$ 1,327,980$ \\
\hline
\end{tabular}

IV = intravenous.

* All numerical data are in Australian dollars and the cost for each item is referred to the year 2011 health care cost.

$†$ Mean difference per patient: $\$ 3281$ favoring titanium cranioplasty but not statistically different $(95 \% \mathrm{Cl} \$-9869$ to $\$ 3308 ; p=0.327)$.

eration. ${ }^{19,19}$ However, the findings of this study would lend support to the hypothesis that surgical technique might be important. A single senior neurosurgeon (S.H.) performed all procedures, and there was a strict adherence to surgical sterility. Prior to this study, at the 2 neurotrauma centers in Western Australia most cranioplasty procedures were performed by relatively junior registrars, as these procedures are generally perceived to be relatively straightforward. However, the dissection of scarred tissue planes and the handling of implants can make maintenance of sterility difficult in inexperienced hands, and this may result in a higher infection rate after cranioplasty.

\section{Assessing Success of Cranioplasty}

There is no widely accepted method by which a cranioplasty is deemed to be successful, and there will always be an element of subjectivity. In this study an attempt was made to make an objective assessment of each component separately.

\section{Cosmetic Assessment}

To be completely successful cosmetically, the cranioplasty material has to be unnoticed, even on close inspection. A minor degree of temporal hollowing was deemed allowable as this is really a consequence of the initial decompression rather than the restorative material. In addition, there are elements of cosmetic outcome that are unrelated to the cranioplasty material, such as skin thickness, hair length and density, and the position of the skull defect. Notwithstanding these factors, the findings of this study would suggest that autologous bone remains a viable option, although overall it was still not as good as titanium cranioplasty.

\section{Functional and Radiological Assessment}

In terms of restoration of cranial coverage, titanium cranioplasties had a clear advantage over autologous bone. In all 31 cases, cranial coverage was complete, with no defects noticeable on clinical palpation and good overlap of the titanium over the cranial surface. In a few cases, the contour was only satisfactory on clinical palpation; however, this was thought to be due to surgical malpositioning rather than a deficiency with the material.

Assessing the autologous bone was slightly more subjective as there are often small gaps where bur holes have been performed. In many ways, making the assessment that there had been a "complete failure" in 7 patients was relatively easy as there were large areas of deficiency, and the soft dura was easily palpable. The assessment of partial failure is more difficult and open to interpretation. Small palpable gaps would suggest failure to restore functional contour, but the working clinical assessment should probably be a combination of clinical palpation and radiological assessment, and, as such, a direct comparison with titanium is problematic. The titanium once positioned does not resorb over time. The bone, however, may have a reasonable contour on palpation with minor defects noted; however, radiological evidence of resorption through both tables of the calvaria bone will certainly reduce the ability to protect the underlying brain from a direct blow and certainly from a penetrating injury. The obvious question remains as to how thin the bone must become before it is deemed not protective. Given that the most severe resorption appears to occur in younger adults, what needs to be established is at what stage does a weakened bone require augmentation, and this requires further investigation.

\section{Cost Analysis}

In each case of absolute cranioplasty failure, the patient requires readmission, a second operation to remove the bone flap, prolonged antibiotic therapy (in the case of infection), a custom-made titanium plate constructed, and readmission for a third surgical procedure. The question addressed in this study is whether it would be more efficacious and cost-effective to insert a custom-made titanium cranioplasty as a primary procedure. Our results showed that, overall, primary titanium cranioplasty was cost-neutral compared with autologous cranioplasty. Although there were costs associated with the custom-made titanium plates, these costs were offset by the extra costs incurred by the operation and hospital stay costs associated with the increase in the number of patients $(16 \%)$ who required secondary cranioplasty after their autologous cranioplasty had failed.

\section{Limitations}

This study has some limitations. First, although this study was successfully powered to detect a difference in clinical efficacy between autologous and titanium cranioplasty, our sample size was too small to detect a potential 
difference in cost-effectiveness. This is because not all patients with bone resorption would require or prefer secondary cranioplasty if they are asymptomatic. Second, although the follow-up period would appear to be adequate, it is possible that the long-term results beyond 12 months after autologous and titanium cranioplasty may further diverge. Third, the assessment of bone resorption, bone fusion, and cosmetic and functional outcome were performed by the senior neurosurgeon who was unblinded to treatment allocation, and this will introduce the possibility of observational bias. Fourth, no measures of patient quality of life or satisfaction are reported. Fifth, there are currently many different types of material available to replace autologous cranioplasty. Whether titanium cranioplasty is more cost-effective than acrylic or bioceramic cranioplasty remains uncertain, and this merits further investigation. A final consideration is the degree to which these results are generalizable to routine clinical practice. Prior to this study, as is probably the case in many centers, cranioplasty procedures were usually delegated to relatively junior staff at the 2 neurotrauma centers in Western Australia. It may be that this contributes to the relatively high incidence of infection reported at our centers and also in the neurosurgical literature. ${ }^{911,16,26}$ Given the results of this study, it may be necessary to reconsider the role of more senior staff in the management of these cases.

\section{Conclusions}

This randomized controlled study showed that primary titanium cranioplasty after decompressive craniectomy was associated with better cosmetic and functional outcomes than primary autologous cranioplasty without increasing overall health care costs. Bone resorption appeared to be more common in young patients who had autologous cranioplasty. Primary titanium cranioplasty should be seriously considered for young patients who require reconstruction of the skull vault following decompressive craniectomy.

\section{Acknowledgments}

This work was partially funded by Western Australian State Health Research Advisory Council (A $\$ 129,500)$. This funding was used to cover the costs of the titanium plates manufactured at Royal Perth Hospital. There was no contribution to the preparation of the manuscript. The corresponding author has full access to the data in this study and has the final decision regarding submission for publication.

\section{References}

1. Aarabi B, Hesdorffer DC, Ahn ES, Aresco C, Scalea TM, Eisenberg HM: Outcome following decompressive craniectomy for malignant swelling due to severe head injury. J Neurosurg 104:469-479, 2006

2. Agrawal D, Hussain N: Decompressive craniectomy in cerebral toxoplasmosis. Eur J Clin Microbiol Infect Dis 24:772-773, 2005

3. Coulter IC, Pesic-Smith JD, Cato-Addison WB, Khan SA, Thompson D, Jenkins AJ, et al: Routine but risky: a multi-centre analysis of the outcomes of cranioplasty in the Northeast of England. Acta Neurochir (Wien) 156:13611368,2014
4. Day RE, Guy DT, Kop AM, Morrison DA: The Royal Perth Hospital method for the design and manufacture of titanium cranioplasty plates. Br J Oral Maxillofac Surg 50:376-377, 2012

5. Di Rienzo A, Iacoangeli M, Rychlicki F, Veccia S, Scerrati M: Decompressive craniectomy for medically refractory intracranial hypertension due to meningoencephalitis: report of three patients. Acta Neurochir (Wien) 150:1057-1065, 2008

6. Dünisch P, Walter J, Sakr Y, Kalff R, Waschke A, Ewald C: Risk factors of aseptic bone resorption: a study after autologous bone flap reinsertion due to decompressive craniotomy. J Neurosurg 118:1141-1147, 2013

7. Ferro JM, Crassard I, Coutinho JM, Canhão P, Barinagarrementeria F, Cucchiara B, et al: Decompressive surgery in cerebrovenous thrombosis: a multicenter registry and a systematic review of individual patient data. Stroke 42:2825-2831, 2011

8. Fisher CM, Ojemann RG: Bilateral decompressive craniectomy for worsening coma in acute subarachnoid hemorrhage. Observations in support of the procedure. Surg Neurol 41:65-74, 1994

9. Gooch MR, Gin GE, Kenning TJ, German JW: Complications of cranioplasty following decompressive craniectomy: analysis of 62 cases. Neurosurg Focus 26(6):E9, 2009

10. Grant FC, Norcross NC: Repair of cranial defects by cranioplasty. Ann Surg 110:488-512, 1939

11. Grant GA, Jolley M, Ellenbogen RG, Roberts TS, Gruss JR, Loeser JD: Failure of autologous bone-assisted cranioplasty following decompressive craniectomy in children and adolescents. J Neurosurg 100 (2 Suppl Pediatrics):163-168, 2004

12. Ho KM, Honeybul S, Lind CR, Gillett GR, Litton E: Costeffectiveness of decompressive craniectomy as a lifesaving rescue procedure for patients with severe traumatic brain injury. J Trauma 71:1637-1644, 2011

13. Honeybul S: Complications of decompressive craniectomy for head injury. J Clin Neurosci 17:430-435, 2010

14. Honeybul S: Decompressive craniectomy: a new complication. J Clin Neurosci 16:727-729, 2009

15. Honeybul S, Ho KM: The current role of decompressive craniectomy in the management of neurological emergencies. Brain Inj 27:979-991, 2013

16. Honeybul S, Ho KM: How "successful" is calvarial reconstruction using frozen autologous bone? Plast Reconstr Surg 130:1110-1117, 2012

17. Honeybul S, Ho KM: Long-term complications of decompressive craniectomy for head injury. J Neurotrauma 28:929-935, 2011

18. Honeybul S, Janzen C, Kruger K, Ho KM: The impact of cranioplasty on neurological function. Br J Neurosurg 27:636-641, 2013

19. Korinek AM, Golmard JL, Elcheick A, Bismuth R, van Effenterre R, Coriat P, et al: Risk factors for neurosurgical site infections after craniotomy: a critical reappraisal of antibiotic prophylaxis on 4,578 patients. $\mathbf{B r} \mathbf{J}$ Neurosurg 19:155-162, 2005

20. Matsuno A, Tanaka H, Iwamuro H, Takanashi S, Miyawaki S, Nakashima M, et al: Analyses of the factors influencing bone graft infection after delayed cranioplasty. Acta Neurochir (Wien) 148:535-540, 2006

21. Polin RS, Shaffrey ME, Bogaev CA, Tisdale N, Germanson T, Bocchicchio B, et al: Decompressive bifrontal craniectomy in the treatment of severe refractory posttraumatic cerebral edema. Neurosurgery 41:84-94, 1997

22. Schuss P, Vatter H, Oszvald A, Marquardt G, Imöhl L, Seifert $\mathrm{V}$, et al: Bone flap resorption: risk factors for the development of a long-term complication following cranioplasty after decompressive craniectomy. J Neurotrauma 30:91-95, 2013 
23. Schwab S, Steiner T, Aschoff A, Schwarz S, Steiner HH, Jansen O, et al: Early hemicraniectomy in patients with complete middle cerebral artery infarction. Stroke 29:18881893,1998

24. Stieglitz LH, Fung C, Murek M, Fichtner J, Raabe A, Beck $\mathrm{J}$ : What happens to the bone flap? Long-term outcome after reimplantation of cryoconserved bone flaps in a consecutive series of 92 patients. Acta Neurochir (Wien) 157:275-280, 2015

25. Wiggins A, Austerberry R, Morrison D, Ho KM, Honeybul $\mathrm{S}$ : Cranioplasty with custom-made titanium plates -14 years experience. Neurosurgery 72:248-256, 2013

26. Yang XF, Wen L, Shen F, Li G, Lou R, Liu WG, et al: Surgical complications secondary to decompressive craniectomy in patients with a head injury: a series of 108 consecutive cases. Acta Neurochir (Wien) 150:1241-1248, 2008

\section{Disclosures}

The authors report no conflict of interest concerning the materials or methods used in this study or the findings specified in this paper.

\section{Author Contributions}

Conception and design: all authors. Acquisition of data: Honeybul, Ho. Analysis and interpretation of data: all authors. Drafting the article: Honeybul, Morrison, Ho, Lind. Critically revising the article: Honeybul. Statistical analysis: Ho, Geelhoed. Administrative/technical/material support: Morrison.

\section{Correspondence}

Stephen Honeybul, Department of Neurosurgery, Sir Charles Gairdner Hospital, Nedlands, Perth, WA 6019, Australia. email: stephen.honeybul@health.wa.gov.au. 